Email: population@pncampus.edu.np

eJournal Site: http://ejournals.pncampus.edu.np/ejournals/ajps/

\title{
Disability Stigma and Discrimination in Nepal: A Study of Pokhara Metropolitan City
}

\author{
Ram Prasad Aryal, PhD \\ School of Development and Social Engineering, Pokhara University, Kaski, Nepal \\ Badri Aryal \\ School of Development and Social Engineering, Pokhara University, Kaski, Nepal \\ Corresponding Author \& Email \\ Ram Prasad Aryal; Email: ramaryalpu@gmail.com
}

Article History

Submitted 19 August 2021; Reviewed 19 September 2021; Accepted 26 October 2021 DOI: https://doi.org/10.3126/ajps.v1i1.43592

\section{Copyright Information: \\ Copyright 2022@ The Author(s). \\ The journal is licensed under a \\ Creative Commons Attribution- \\ ShareAlike 4.0 International \\ License. \\ (c) (i) (2) \\ Published by \\ Department of Population Studies \\ Prithvi Narayan Campus \\ Tribhuvan University \\ Pokhara, Nepal}

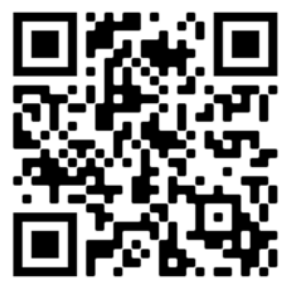

Scan to Access eJournal

\begin{abstract}
Stigma and discrimination attached to disability are not new phenomenon in Nepal. People, irrespective of disability status, have been aware of these phenomena since long history of human kind from socio-cultural perspectives prevalent in Nepalese society. In this context, people with disability have been facing stigma and discrimination in their family and society. There are tremendous disruptions in attaining quality of life of the people. However, there is a dearth of such studies attached to disability, especially in the present contexts of socio-cultural transformation and era of assistive devices. This study focuses on root causes of disability stigma and discrimination in people with disability in Pokhara Metropolitan City. It adopts qualitative research approach, following in-depth interview to people with disability using semistructured questionnaires in the city. This study investigated that there are heavily loaded stigma and discrimination in people with disability, especially in women in-migrants in their place of origin. It concludes that gender, caste, class, and
\end{abstract} residence are intrinsically linked with the daily lives of the people. This study has important policy implications in reducing stigma and discrimination, and in attaining quality of lives of the people.

Keywords: Disability, discrimination, in-migration, Nepal, stigma 


\section{Disability Stigma and Discrimination in Nepal: A Study of Pokhara Metropolitan City}

\section{Introduction}

Going through historical context of disability in Nepal, various research reports suggest that people believe being disability in present life is as a result of an individual's sinful past actions in his/her previous life (Thapaliya, 2016; Timilsana, 2018). Nepalese cultural understanding is that the privileges and deficits of our current life are attributed to the sins in one's past life (Gabel \& Danforth, 2008). If an individual is disabled, it is regarded as a result of the sins of one's past lives. Therefore, people often hide their disability due to a number of socio-cultural norms, values and pressures. In Nepal, prevalence rate in some form of disability in accordance with census report of 2011 is two per cent of the total population (Khanal, 2014). Researchers, policy makers, and planners who are working in the Nepalese disability sectors estimate that national disability figure is actually far higher. They attribute this to poverty, poor health and maternal care facilities, geographical variations, the People War (or Maoist War) and the recent earthquake (Thapaliya, 2016).

For a long time, disability in Nepal has primarily been a family concern and occasionally it has received some focus from public charity (in bigger urban centres like Kathmandu and Pokhara) and private philanthropy (in and around popular religious locations). Within a family also it is still a common practice to use the stigmatizing tag of "disfavour" with disabled conditions of family members and most of the families in Nepal still consider disability as a punishment for all the depravities and wickedness, persons with disability have committed in their past lives (Subedi, 2012; Timilsana, 2018). Besides, the burden of disability is mostly put on the mothers of child with disability.

The beginning of disability policy in Nepal is quite recent. In the following year of International Year of Persons with disability as proclaimed by the United Nations in 1981, Nepal enacted the Disabled Protection and Welfare Act (GoN, 2006). Moreover, it was only after 1992, the series of different legislations started to emerge such as the Education Act of 1992, Child Rights Acts of 1992 and Local Self-Government Act 1999 that have indirectly helped to bring forward people with disability (PWDs) conditions closer to the policy makers. The important changes have been only initiated after 2006, following the decade long conflict that has forced Nepal to provide political high priority to social inclusion and human rights, including those of PWDs. This paper is intended to explore root causes of stigma and discrimination prevalent in Nepalese context, especially for in-migrants and native residents with disability of Pokhara.

\section{Literature Review}

There is hard to compare disability data between various countries as there are differences in data collection designs, definitions, concepts, and methods (Elwan, 1999). However, it is believed that around one billion people, 15 per cent of the total population, experience some form of disability in the world (United Nations, 2018). Among them, one-fifth of the global people with disability experience significant disabilities. Among the total people with some form of disability, 80 per cent of the people with disability live in the developing countries. Thus, disability prevalence is remarkably higher in developing countries. Likewise, various sources of disability study show various figures of people with disability in Nepal. The 2011 census reports that there are 513,321 people with disability in Nepal (nearly two per cent of the total population). Likewise, the 2011 National Living Standards Survey Report reports that 3.6 per cent of the total population are people with disability in Nepal (Holmes et al., 2018). There are around 15 per cent people with disability of the total population in the country (Eide et al., 2016). 


\section{Disability Stigma and Discrimination in Nepal: A Study of Pokhara Metropolitan City}

Disability is often blamed on misdeeds of either ancestors, parents, or the person with disability. As a result, people with disabilities may be thought to be a source of shame. There are misconceptions that they are unable to contribute to family and society financially. Furthermore, it is believed that they are not able to have a good relationship in family and society. These misconceptions contribute to the stigma and discrimination in family and society. People with disabilities face attitudinal barriers including prejudice, stereotypes, and low expectations. These attitudinal barriers cause negative responses such as pity, anxiety, and avoidance (Scior, 2016). In contrast to severe disability, people with disabilities who can participate in their communities' experience fewer stigmas than those with more severe disabilities. Females who are disabled are doubly disadvantaged due to gender and their disability status. Likewise, people with disabilities in rural areas may experience more stigma and discrimination than in urban areas (Njelesani et al., 2018).

There is a short history of disability studies in Nepal. The Report on the Sample Survey of Disabled Individuals in Nepal conducted in 1981 was the first study on disability in the country (VRG, 1996). Therefore, research on disability has a fairly short history in Nepal. It is almost neglected subject matter, not only in development policies and planning but also in literature in the field of disability. This is not only in Nepal but also in the wider South Asian region (Sonpal \& Kumar, 2012). With these contexts on disability, this study focuses on investigating root causes of disability stigma and discrimination in Pokhara.

\section{Research Method}

In this study, qualitative research approach is used with a view to capture the lived experiences of people with disability as it includes an interpretive approach to an event with socio-cultural perspectives (Taylor \& Bogdan, 1998). Moreover, it makes us to gain insights into the lived experiences of people with disability through the provision of greater details and rich descriptions (Silverman, 2004). We intended to select people with disability located in Pokhara Metropolitan City through organizations working in the field of disability. In Nepal, significant numbers of people, irrespective of age and sex, have been making their destinations into cities for the last few decades, leaving their place of origin (Suwal, 2014). Even in the case of people with disability, it was also presumed that they might have in-migrated into cities as development activities like care homes and better health services have been centralized there. In this study, thematic analysis, meaning making approach has been used for analysing data (Bryman, 2012; Guest, MacQueen, \& Namey, 2012). Themes have been derived from the field data relative to a specific research objective and semi-structured research interviews (Wengraf, 2001). There were altogether 25 research participants including heterogeneous groups of people aged 23 years and above - unmarried, currently married and remarried, widower, and separated from home. The heterogeneous groups of people belonged to Brahman/Kshetri, known as a high caste people, followed by Janajati, indigenous people, and Dalit people belonging to the lowest socio-economic and caste groups, so called untouchable caste/tribes of people in Nepal. Likewise, among them, few numbers of participants who could not convey their information due to their disability criteria of deaf, vision loss, and dumb by birth or later were visited at their office. There were altogether three persons, two males and one female, having such criteria whom interviews were taken with Dobhase (interpreter), a lady, conveying each question of the interview schedule. There were 18 males and 7 females as participants in this study. These participants have been classified into three categories- profound disability, severe disability, and moderate disability (World Health Organization, 2011). There were three 


\section{Disability Stigma and Discrimination in Nepal: A Study of Pokhara Metropolitan City}

participants with profound disability, 20 participants with severe disability, and two participants with moderate disability in accordance with nature of their disability in this study. They had been provided identity card with red, blue and yellow colour respectively as per the above three categories of disability.

\section{Findings of the Study}

\section{Disability Stigma and Discrimination}

After being disabled with an accident or anything else, people with disability find themselves economic stigma about their life. They find themselves in fear of spending their remaining life from economic perspectives as they cannot work themselves actively as much as other people can do. As a result, they have to depend on others' earnings and have to request other people for livelihood, irrespective of family, relatives and societal people. Furthermore, they have not been introduced with other people with disability and they do not have an idea on how to cope with challenges as being disabled in family and society.

People, irrespective of disability status, are aware of family, and social discrimination prevalent in Nepalese society as a result of disability. They have a clear picture of events of ostracization and discrimination associated with disability as these events are linked up with karma of previous births in Nepalese society. Disability is considered as a result of bad karma done either in the present or in the past. Thus, people with disability are heavily stigmatized and discriminated in Nepalese society. With this socio-cultural context, people find stigma once they get disability.

People without disability, irrespective of family and society, do not pay attention towards addressing problems of people with disability. Although people with disability have been suffering a lot due to their disability, neither family members nor societal people want to pay attention to make their life comfort and easy addressing their problems as much as possible. Rather, the people without disability show their ignorance pretending that they know nothing about the disabled person's problem either at home or at their society. With this context, Laxmi, who has been facing problem of spinal cord injury since her childhood, shares her own experiences like this way:

Family does not give priority to us. Likewise, people do not encourage our work saying that Nepal Government provides us allowance. People question us on every step of our work rather than supporting us; they think we should remain only in house, not roaming here and there around the places. Family members think us as burden for the family. They think if we have died earlier it would be better. Despite of our disability we love our body equally like people without disability. My parents ignore me; they do not support and care me. It has already been five years I have stayed in Pokhara; my parents haven't come to see my present situation yet. They even do not care how I am surviving here, managing my day to day expenditure, and so on.

Laxmi, Dalit Unmarried Female Aged 26 years

She further added how she felt heartbroken from the behaviour of her father in this way:

I have come here [Pokhara] to purchase my wheel chair. A person has inquired me whether I was interested on trainings like sewing. I requested my father for this opportunity, but he did not respond me positively and did not feel easy to support me financially. He told me to do whatever I like. He did not encourage me. Then, I initiated myself for the process of the training. As I don't get any support from my own parents, I feel like heartbroken. Till today they [Parents] have not come here [Pokhara] to see my situation.

Laxmi, Dalit Unmarried Female Aged 26 years 


\section{Disability Stigma and Discrimination in Nepal: A Study of Pokhara Metropolitan City}

Family members do not want to expose their children with disability outside home. They often presume that their children with disability are the outcome of performing sinful activities in the previous life. Therefore, family members hide their children leaving at home even if they need to go somewhere else. They do not want to expose such person to the societal people where gatherings occur such as in puja, religious functions of the relatives or neighbours. In this study, one of the male participants, shares his bitter experiences of leaving him alone by his family members in this way:

Once, all of my family members had gone to Puja leaving me alone at night after I slept. Since I am a person with disability, they did never think of me I should go along with them. Early in the morning, I woke up and searched my family. There was no one around me at home. Then, I went to look for them and I fell down from the terrace farmland, 2-3 steps down. I got injured at that time. From that day a kind of fear arose in my mind. This happened when I was 8 years old.

Khom, Brahman Married Male Aged 36 Years

Similarly, Pushpa Raj, one of the male participants, shares his information listened from others like this way:

I have listened in several villages about the discrimination. For example, a family feels shy to expose their children with disability outside during marriage ceremonies held in the same family or outside. They cook food for them only and leave them in the home. The family locks down the people with disability, sometimes tying them. That type of discrimination is seen even today.

Pushpa, Brahman Married Male Aged 43 Years

Family members do not treat well to the member with disability after his/ her disability. In Nepalese society, there is likely to show different behaviour to the person with disability on the basis of his/her contribution to the family from the economic perspective. It is well known that person with disability may not contribute to his/her family economically and socially. As a result, the person with disability finds the behaviour of his family different after being disabled. When the person has to depend totally on other, family members misbehave him/her badly. In this study, one of the male research participants, who lost his leg after a bus accident in the course of driving the bus, expresses his feelings in this way:

There lies a lot of discrimination. Even my children whom I have brought up and taken care of them properly, to whom I have spent money for their education are now mistreating me. I have to survive like by begging. My son used to beat me when I used to be at home. Despite being disabled, I earn money; I care them but they do not see my contribution. They scold me; beat me which has made me feel very bad.

Bharat, Kshetri Widower Aged 57 Years

In this context, Bharat further states that his relatives do not like him while visiting them in this way:

My relatives discriminate me. They talk unnecessary things about me. When I went to the place [district] they told me not to go there. 'Why do you have to come here?' they said. I felt very painful at that moment. When I start remembering my life, I do not feel sleepy. I stare whole night remembering all those bad memories. Thousands of things strike in my mind. I sleep just 2 hours during night.

Bharat, Kshetri Widower Aged 57 Years

Children with immature age, particularly below age of 15 years, coupled with economically and socially deprived children in Nepalese society are heavily ostracized 


\section{Disability Stigma and Discrimination in Nepal: A Study of Pokhara Metropolitan City}

and discriminated. Especially in rural areas while going out from home with a view to study at school, to graze cattle at grassland, and going somewhere else alone. Children with good economic and social background often dominate those children with disability with poor socio-economic background providing worn out clothes. The physically well children tease children with disability calling them insulting words like "lata, lati [dumb]", that hurts enormously in children living with disability in Nepal, especially in rural areas. This is common phenomenon while being in school age. In this context, Asha who has lost both hearing and eye vision whose information was obtained with the support of Dobhase lady (interpreter) in the course of taking face to face in-depth interview shared her experiences of ostracization while going to school at her child age like this way:

I used to study in the school in my village. I was only one deaf student in my school. I was called as "Lati". At that time, I used to be very angry. I also left the school because of the insult they made on me. My mother used to say, "Go to school". But I did not care of it. There used to be many quarrels at my village regarding my issue. People used to tell me- "Foolish". These things made me very sad. Asha, Janajati Married Female Aged 36 Years

People without disability, neighbours, ostracize deprived people with disability heavily because of caste and fragile socio-economic background. There are more than hundred castes and ethnic tribes in Nepal, categorized so called touchable and untouchable castes and tribes. People belonging to high caste dominate the people with so called untouchable castes and tribes in general. Furthermore, people with disability and lower caste groups are adversely ostracized by their neighbours, in general. The parents of the person with disability are also charged for having son and daughter with disability born at home which is attributed to curse and sinful activities done in the current or previous birth. If there is a quarrel between people without disability and the people with disability, people with disability are charged for their disability as a punishment given by God. In this context a female charged with one of the so called untouchable caste shares her sad experiences of being ostracized in this way:

People living close to my house ostracize me thinking of my pitiful condition for livelihood due to my blindness. These people ostracize me telling that studying anything is futile for people with blind because they [People with disability] cannot use knowledge anywhere else. I have a deep bad feeling that I was told not to study by family members, to some extent, and neighbours. People charge me that being blind is the outcome of previous life. People think that I might have done sin in the previous life so that I have been blind as outcome of previous sin. Even if there is a quarrel of parents with neighbours, the neighbours tell us that I am blind because of sin done in the previous life by our parents. If I have a quarrel with neighbours for a reason, they respond me that I am not a good person that's why God has punished me as disabled person.

Mina, Dalit Unmarried Female Aged 27 Years

In Nepalese society, there are people without disability who really like to talk about third person's characteristics either positive or negative characteristics while meeting with each other. Although this is unethical to talk about the third person's negative characteristics in general that hurts the person badly, it has been a part of life in Nepalese society. Furthermore, the people without disability have more things to comment on people with disability from the prevalent socio-cultural contexts to economic aspects of the people living with disability. In this regard, one of the male research participants, shares his own experiences like this way: 


\section{Disability Stigma and Discrimination in Nepal: A Study of Pokhara Metropolitan City}

I have heard misbehaviour faced by other people with disability. First and foremost, family members mistreat people with disability badly. Family, mother, father, and brothers do not treat them equally. They treat them differently. Everyone's thought is not same. That's what I have heard that people with disability are treated differently. In some of the places, parents ostracise their offspring with disability. As a person with disability, we cannot earn money for our livelihood. We cannot walk without support. We cannot work like those persons who are not disabled. We have to walk and survive, relying on other's support. That's why brothers, parents, sisters and neighbours ostracise us.

Bir, Janajati Married Male Aged 28 Years

In this regard, Asha, one of the female research participants shares her experiences on how people without disability ostracize people with disability everywhere in this way:

I have known about such acts [Ostracizations]. There is a person with poor eyesight close to our house. One eye is okay but the sight of another eye is very weak. The person is not loved by other people. We are also people with disability. We feel sorry on that.

Asha, Janajati Married Female Aged 36 Years

Villagers walking on the street beside house once compared the woman with disability as lower than that of domestic animal. Dhana, one of female research participants, shares her bitter experiences in this way:

After the event [fell down from the tree], I spent two-three years at my village. It was also bad for everyone in my family as my age was working age and I could not work. My son was only 8 months old. Villagers' attitude towards me was not good. "If you had been cattle, you would be slaughtered for meat but you are futile being disabled", they told me bitterly. The living environment around me was not good. Many people in the village had also bad feeling on me. It would be good for me if I could have better place in urban area to stay because my hands are still workable. I could not forget bad feelings of the accident up to three years [in village]. I had bitter feelings in a greater extent. One who is in village can have such kinds of bad feelings. Villagers used to say it would be better for me to die rather than to be survive so that soul could get a peace.

Dhana, Janajati Separated Female Aged 28 Years

Bir Bahadur, who is one of male research participants, shared his experiences on how people with disability are treated badly in this way:

Our own sisters, relatives, community people, and even social workers do not look at us positively. Some people blame us verbally and some people mistreat us with their eyes. My house is away from Bhimad [Tanahu district]. I have experienced many difficulties. So called social workers, own brothers and neighbours put us down due to our blindness. They mistreated me telling blind, deaf, handicapped and only eater. I felt very sorry. I thought of such feeling that everyone, including family members, neighbours, so called social workers ostracized us in such a situation of disability. I have not so much listened to their mistreated words directly. But friends and relatives said to me, "You are mistreated badly telling about you [blind and so on]". In the village, people keep people with disability down. People think that this person [Bir Bahadur] does not have any way of surviving in life. They place me at down level in comparison to others. They ostracize me.

Bir, Janajati Married Male Aged 28 Years 


\section{Disability Stigma and Discrimination in Nepal: A Study of Pokhara Metropolitan City}

\section{Discussion}

Looking at disability in Nepalese perspective, there is a dichotomy in treating with people with disability in the country as there are two perspectives - one bad treatment and the other one good treatment. This paper is concerned with bad treatment on people with disability. Nepalese people have their own belief that people with disability must have done some bad karma in the present or in the past life so that they have to face tremendous difficulties and hardships in their present life.

Most of the people in Nepal consider that disability is taken as a heavy economic burden in the family and society. The reason behind this is that the people with disability can't do significant work for the earnings for their survival and need to depend on other people without disability. In this context, one of the female participants, Sushma who has gained software engineering degree and working as an engineer shares her own experiences like this way: "It is all about people's perception. They perceive that people with disability like us cannot do anything. They have superstitious beliefs on us".

In Nepalese society, it is believed that people with resources, either in terms of economic, social or anything else are very important as there is likely to have reciprocity when needed. People without disability often seek reciprocity with each other. They also find that people with disability do not have capacity to do reciprocity behaviour in their society as they are supposed to be only receivers, not givers. This can be analogy with the case of Human Immunodeficiency Virus and Acquired Immunodeficiency Syndrome, focused on people living with HIV written in the context of Africa or anywhere else (See Sen, Aguilar \& Goldbach, 2010). Furthermore, people without disability think of that the people with disability cannot stand themselves socially and economically. In this way, any expectation from the people with disability would be futile for the people without disability. That's why most of the people without disability do not treat well to the people who are living with disability.

People with disability are viewed as sinners in Nepalese socio-cultural contexts as disability is considered as an outcome of bad works done in the past, either in the present life or in the previous births. The perception of bad karma done in the past life is deeply rooted in Nepalese society, especially in the rural Nepal. Physical impairment is considered as a form of curse or punishment given by God. Therefore, people without disability often do not like to treat the people with disability well from their heart as they are taken as a sinner. People with disability feel their identity spoiled because of their stigma, discrimination, and life disruption. As explained above, they are heavily ostracized and discriminated against in family and society.

\section{Conclusion}

This study suggests that there are heavily loaded stigma and discrimination in people with disability, especially in women in-migrants in their place of origin. The stigma and discrimination differ based on gender, marital status, caste, class, and residence. Indeed, better access to resources determines degrees of stigma and discrimination in family and society. This study concludes that the root causes of stigma and discrimination in people with disability are more likely to be considered as economic and social burden in family and society. People without disability believe that there would not be reciprocity from the people with disability, presuming them, only receivers, not givers in family and society.

\section{Acknowledgements}

We are very grateful to University Grants Commission Nepal for providing us fund for faculty research that made this research possible. 


\section{Disability Stigma and Discrimination in Nepal: A Study of Pokhara Metropolitan City}

\section{References}

Bryman, A. (2012). Social research methods. Oxford, UK: Oxford University Press.

Eide, A. H., Neupane, S., \& Hem, K. G. (2016). Living conditions among people with disability in Nepal. Trondheim, Norway: SINTEF Technology and Society.

Elwan, A. (1999). Poverty and Disability: A Survey of Literature. Washington, D.C.: The World Bank.

Gabel, S. L. \& Danforth, S. (2008). Disability \& the Politics of Education: An International Reader. New York: Peter Lang.

GoN (2006). Definition and classification of disability in Nepal, Government of Nepal, revised in 2006.

Guest, G., MacQueen, K. M., \& Namey, E. E. (2012). Applied Thematic Analysis. Los Angeles: Sage Publications.

Holmes, R., Samuel, F., Ghimire, A., \& Thewissen, S. (2018). Nepal's cash allowances for children with disabilities. London: Overseas Development Institute Report.

Khanal, S. P. (2014). Persons with Disability and Their Characteristics. Population Monograph of Nepal, Vol. II, 351-346.

Njelesani, J., Hashemi, G., Cameron, C., Cameron, D., Richard, D., \& Parnes, P. (2018). From the day they are born: a qualitative study exploring violence against children with disabilities in West Africa. BMC Public Health, 18(1), 1-7.

Scior, K. (2016). Towards Understanding Intellectual Disability Stigma: Introduction. In Intellectual Disability and Stigma (pp. 3-13). Palgrave Mcmillon, London.

Sen, S., Aguilar, J. P., \& Goldbach, J. (2010). Does social capital act as a buffer against HIV risk among migrant men in Sub-Saharan Africa? Journal of HIV/AIDS \& Social Services, 9(2), 190-211.

Silverman, D. (2004). Doing Qualitative Research: A Practical Handbook. London: Sage.

Sonpal, D. \& Kumar, A. (2012). Whose reality counts? Notes on disability, development and participation. Indian Anthropologist 42(1), 71-90.

Subedi, M. S. (2012). Challenges to measure and compare disability: A methodological concern. Dhaulagiri Journal of Sociology and Anthropology, (6), 1-24.

Suwal, B. R. (2014). Internal Migration in Nepal. Population Monograph of Nepal. Vol. I, 241-243.

Taylor, S. J., \& Bogdan, R. (1998). Introduction to Qualitative Research Methods: A Guidebook and Resource (3rd ed.). New York: Wiley.

Thapaliya, M. P. (2016). A Report on Disability in Nepal. Christchurch, New Zealand: University of Canterbury.

Timilsana, B. K. (2018). Women with Disabilities in Nepal. The Saptagandaki Journal, (9), 17-25.

United Nations (2018). Disability and Development Report: Realizing the Sustainable Development Goals by for and with Persons with Disabilities. New York: United Nations Publication.

VRG (1996). A Situation Analysis of Disability in Nepal. Submitted to UNICEF, Valley Research Group, Lalitpur.

Wengraf, T. (2001). Qualitative research interviewing: Biographic narrative and semistructure methods. London: Sage.

World Health Organization (2011). World Report on Disability. WHO Press: Geneva. 